\title{
Intermittent or continuous occlusion of hepatic inflow
}

\author{
Radojkovic $\mathrm{M}^{1}$, Stojanovic $\mathrm{M}^{1}$, Stanojevic $\mathrm{G}^{1}$, Bagur $\mathrm{N}^{2}$, Jeremic $\mathrm{L}^{1}$, Jovanovic $\mathrm{M}^{3}$, \\ Damnjanovic $Z^{3}$, Katic $\mathrm{V}^{4}$, Kovacevic $\mathrm{P}^{1}$
}

Surgery Department, Medical School, University of Nish, Nish, Serbia. milan.radojkovic@medfak.ni.ac.rs

\begin{abstract}
The aim of the study: The aim was to compare the effects of intermittent and continuous inflow occlusion on liver I/R injury in an experimental model.

Method: The experiment was done using the Wistar rats that underwent continuous and intermittent inflow liver vascular occlusion. Blood and liver tissue samples were taken and parameters of hepatic ischemia/reperfusion injury were analyzed and compared.

Results: Serum activities of ALT, AST and LDH were significantly higher and ALP activity and albumin concentration were markedly lower in rats with continuous liver ischemia. Also, histopathological examination revealed more severe changes in animals with continuous liver vascular occlusion.

Conclusion: The results of biochemical assay and histopathological examination were concurrent, both indicating more serious parenchymatous damage caused by continuous hepatic pedicle clamping. Study results clearly demonstrated a better tolerance of the liver to intermittent Pringle maneuver (Tab. 1, Fig. 5, Ref. 9). Full Text in PDF www.elis.sk.

Key words: liver, ischemia/reperfusion, injury.
\end{abstract}

Despite technical advances, the prevention of bleeding from a resected liver parenchyma remains a serious problem and is of major concern during liver resection and transplantation. The application of inflow and inflow/outflow liver vascular occlusion methods enables to perform a safe, bloodless and precise anatomic hepatic resection. However, the common major disadvantages of these methods include serious hemodynamic disturbances and liver ischemia/reperfusion (I/R) injury, limiting the time of their safe usage. The possibility to increase the liver tolerance of temporary normothermic occlusion and, thus, expanding the duration of safe vascular clamping, is an objective of numerous clinical and experimental studies. The safety of intermittent and continuous clamping regarding clamping-caused hepatic $\mathrm{I} / \mathrm{R}$ injury is still a major controversy in liver surgery. Each clamping model was both experimentally and clinically supported, providing controversial data on their safety. Intermittent clamping was reported to attenuate liver damages in a long-term ischemia as compared to continuous clamping $(1,2,3)$. However, in a short-term ischemia (not exceeding 1 hour) liver injury was reported to be similar in both clamping methods $(4,5)$ or even decreased when using the continuous clamping $(6,7)$. Therefore, comparative data on advantages and drawbacks of these two clamping methods in short-term

\footnotetext{
${ }^{1}$ Surgery Department, Medical School, University of Nish, Nish, Serbia, ${ }^{2}$ Anesthesiology Department, Clinical Center, Nish, Serbia, ${ }^{3}$ Vascular Surgery Department, Clinical Center, Nish, Serbia, and ${ }^{4}$ Pathology Department, Medical School, University of Nish, Nish, Serbia

Address for correspondence: M. Radojkovic, Klinicki centar, Bul. Z. Dindica 48, 18000 Nis, Serbia

Phone: +381.69 .716567$
}

normothermic liver ischemia are still lacking. The aim of the present study was to compare the effects of intermittent and continuous inflow occlusion on liver I/R injury in an experimental model.

\section{Methods}

\section{Experimental animals}

The experiment was done using the healthy adult Wistar rats, both gender, weighing $290-400$ g, aged $1.5-3$ months. Animals were divided into the three groups: $\mathrm{C}$ group - continuous hepatic pedicle clamping (HPC) lasting 45 minutes, I group - intermittent HPC: three 15 minute periods of ischemia separated by 5 minute reperfusion periods and the control group (CG) - without surgery. The Groups $\mathrm{C}$ and I consisted of 40 rats each and CG consisted of 10 rats. None of the animals received any pharmacological agent preoperatively.

\section{Surgical procedures}

Rats were anesthetized with intramuscular injection of $10 \%$ ketamine hydrochloride ( $0.3 \mathrm{ml}$ per animal). Midline incision was performed and hepatic pedicle was identified and clamped using non-absorbable polypropylene suture, double wrapped around the whole hepatic pedicle. The procedures and postoperative course were uneventful.

\section{Biochemical assays}

Blood samples were taken on the 1, 2, 3 and 7 postoperative day (POD) from 10 rats respectively of the $\mathrm{C}$ and I group per each POD (subgroups C1, C2, C3, C7 and I1, I2, I3, I7 each consisting of 10 animals) by a puncture of the left myocardial ventricle 
Tab. 1. Biochemical assay results (mean values).

\begin{tabular}{|c|c|c|c|c|c|}
\hline $\begin{array}{l}\text { Albumin } \\
(\mathrm{gr} / \mathrm{L})\end{array}$ & $\mathrm{CG}=32.0 \pm 1.9$ & $\begin{array}{l}\mathrm{I} 1=28.8 \pm 4.3 \\
\mathrm{C} 1=26.9 \pm 8.0 \\
*_{\mathrm{nss}}\end{array}$ & $\begin{array}{l}\mathrm{I} 2=29.0 \pm 4.7 \\
\mathrm{C} 2=28.5 \pm 2.7 \\
* \mathrm{nss}\end{array}$ & $\begin{array}{l}\mathrm{I} 3=29.0 \pm 3.4 \\
\mathrm{C} 3=27.5 \pm 9.7 \\
*_{n s s}\end{array}$ & $\begin{array}{l}\mathrm{I} 7=31.8 \pm 3.5 \\
\mathrm{C} 7=30.4 \pm 4.8 \\
* \mathrm{nss}\end{array}$ \\
\hline $\begin{array}{l}\text { ALP } \\
(\mathrm{U} / \mathrm{L})\end{array}$ & $\mathrm{CG}=258.6 \pm 81.7$ & $\begin{array}{l}\mathrm{I} 1=99.0 \pm 29.8 \\
\mathrm{C} 1=171.7 \pm 74.7 \\
*_{\mathrm{p}}=0.009<0.01\end{array}$ & $\begin{array}{l}\mathrm{I} 2=110.3 \pm 34.0 \\
\mathrm{C} 2=174.9 \pm 126.3 \\
* \mathrm{nss}\end{array}$ & $\begin{array}{l}\mathrm{I} 3=154.6 \pm 49.6 \\
\mathrm{C} 3=132.9 \pm 73.6 \\
* \text { nss }\end{array}$ & $\begin{array}{l}\mathrm{I} 7=137.6 \pm 79.0 \\
\mathrm{C} 7=201.0 \pm 111.2 \\
* \mathrm{nss}\end{array}$ \\
\hline $\begin{array}{l}\text { ALT } \\
(\mathrm{U} / \mathrm{L})\end{array}$ & $\mathrm{CG}=137.7 \pm 24.4$ & $\begin{array}{l}\mathrm{I} 1=328.0 \pm 219.8 \\
\mathrm{C} 1=504.1 \pm 263.9 \\
* \mathrm{nss}\end{array}$ & $\begin{array}{l}\mathrm{I} 2=78.3 \pm 13.8 \\
\mathrm{C} 2=87.6 \pm 32.3 \\
*_{\mathrm{nss}}\end{array}$ & $\begin{array}{l}\mathrm{I} 3=45.9 \pm 22.4 \\
\mathrm{C} 3=61.1 \pm 21.2 \\
*_{\mathrm{nss}}\end{array}$ & $\begin{array}{l}\mathrm{I} 7=45.8 \pm 11.7 \\
\mathrm{C} 7=64.9 \pm 12.9 \\
*_{\mathrm{nss}}\end{array}$ \\
\hline $\begin{array}{l}\text { AST } \\
(\mathrm{U} / \mathrm{L})\end{array}$ & $\mathrm{CG}=292.3 \pm 37.4$ & $\begin{array}{l}\mathrm{I} 1=542.2 \pm 235.1 \\
\mathrm{C} 1=820.9 \pm 282.4 \\
* \mathrm{p}=0.041<0.05\end{array}$ & $\begin{array}{l}\mathrm{I} 2=308.5 \pm 113.4 \\
\mathrm{C} 2=411.7 \pm 165.9 \\
* \mathrm{nss}\end{array}$ & $\begin{array}{l}\mathrm{I} 3=172.9 \pm 53.2 \\
\mathrm{C} 3=327.9 \pm 75.1 \\
* \mathrm{p}=0.000<0.001\end{array}$ & $\begin{array}{l}\mathrm{I} 7=247.3 \pm 51.8 \\
\mathrm{C} 7=254.4 \pm 114.9 \\
* \text { nss }\end{array}$ \\
\hline $\begin{array}{l}\mathrm{LDH} \\
(\mathrm{U} / \mathrm{L})\end{array}$ & $\mathrm{CG}=1070.3 \pm 196.3$ & $\begin{array}{l}\mathrm{I} 1=789.4 \pm 362.4 \\
\mathrm{C} 1=1353.4 \pm 650.2 \\
* \mathrm{p}=0.034<0.05\end{array}$ & $\begin{array}{l}\mathrm{I} 2=1942.9 \pm 1044.3 \\
\mathrm{C} 2=1161.2 \pm 460.7 \\
* \mathrm{p}=0.034<0.05\end{array}$ & $\begin{array}{l}\mathrm{I} 3=808.1 \pm 213.0 \\
\mathrm{C} 3=1308.2 \pm 432.3 \\
* \mathrm{p}=0.013<0.05\end{array}$ & $\begin{array}{l}\mathrm{I} 7=1020.9 \pm 211.5 \\
\mathrm{C} 7=2104.3 \pm 931.4 \\
* \mathrm{p}=0.001<0.01\end{array}$ \\
\hline
\end{tabular}

Legend: shadow - statistical significance in comparison to CG; * - statistical significance between I and C subgroups, nss - no statistical significance

through the midline thoracoabdominal incision. Serum activities of ALT, AST, LDH and ALP and the concentration of albumin were measured. The detected values were compared between the relevant subgroups for each POD respectively.

\section{Histopathological (HP) examination}

On the same occasion, liver tissue samples were also taken, fixed with $10 \%$ formaldehyde, stained using hematoxylin and eosine (HE) and analyzed with light microscopy. The observed HP changes caused by liver $\mathrm{I} / \mathrm{R}$ injury were compared.

\section{Statistical analysis}

The obtained values at the relevant time points between the subgroups were compared using the independent-samples $t$ test. The $p$ values lower than 0,05 or 0,01 were considered statistically significant.

\section{Results}

The results of biochemical assay are presented in Table 1. In the liver tissue samples of $\mathrm{C} 1$ rats (first POD), numerous hepatocyte adaptation mechanisms (including cellular atrophy, hyperplasia and condensation), different types of degeneration and necrosis were observed (Fig. 1). Unlike these HP findings, in the liver tissue samples of I1 rats, there was no necrosis, heavy fatty degeneration or inflammation and in some parts of the acinuses (portal areas and Kupffer cells) there were no HE changes at all (Fig. 2). More intense and diverse HP findings in $\mathrm{C} 1$ rats indicated more severe ischemic injury after continuous HPC compared to the intermittent one.

The same pattern of HP changes was also observed in the second POD: in C1 rats, necrosis was diffuse and more intense, along with different types of degeneration (mainly fatty) and portal areas dilatation. Necrosis and inflammation was observed for the first time in $\mathrm{I} 2$ rats, but it was sporadic, multifocal and without heavy degeneration. In the liver tissue samples of $\mathrm{I} 3$ rats (third POD), regenerative hepatocytes were found indicating a regeneration (Fig. 3 ), unlike $\mathrm{C} 3$ rats where there were no such indicators, which also suggested a more severe ischemic injury after continuous inflow vascular occlusion.

Figure 4 shows the liver tissue sample of a $\mathrm{C} 3$ rat: bridging and spotty necrosis with microvacuolar degeneration (HE, x20).

In the HP samples of both $\mathrm{I} 7$ and $\mathrm{C} 7$ rats (seventh POD), regenerative activity was observed. However, it was more intense and massive in $\mathrm{I} 7$ rats and accompanied with initial fibrosis in comparison to $\mathrm{C} 7$ animals where the regeneration was not diffuse and the fibrosis was absent (Fig. 5).

\section{Discussion}

A statistically significant serum hypoalbuminemia was detected in both $\mathrm{C} 1$ and $\mathrm{I} 1$ subgroup compared to $\mathrm{CG}$ on the first POD, which indicated a decreased postischemic protein synthesis in the liver. However, hypoalbuminemia, although still present, was not statistically significant in animals with intermittent HPC compared to CG on 2, 3 and 7 POD (subgroups I2, I3 and I7), suggesting a gradual restoration of liver synthetic function. Unlike these results, in C3 rats, a statistically significant hypoalbuminemia persisted, what demonstrated a slower recovery, i.e. more severe liver injury caused by continuous HPC. Serum activities of both ALT and AST were significantly elevated in both C1 and I1 subgroups (first POD) compared to CG. Furthermore, activities of these enzymes were markedly decreasing on 2, 3 and 7 POD, both in rats with continuous and intermittent HPC. But, while ALT activity was returning to normal more promptly, AST activity remained elevated in C2 (statistically significant), I2 and C3 subgroups compared to CG. Also, compared to each other, serum AST activities were significantly higher in $\mathrm{C} 1$ and $\mathrm{C} 3$ subgroups in comparison to I1 and I3 subgroups. These results (with peak serum ALT and AST activities on the first POD) demonstrated a more intense liver necrosis in rats with continuous HPC. Similar findings were reported by other authors $(1,2,8)$. Serum LDH activity was elevated in all subgroups of rats with continuous HPC on 1, 2, 3 and 7 POD (C1, C2, C3 and C7) and only in I2 rats with intermittent HPC (second POD) in comparison to CG. This finding correlated with the occurrence (first POD in rats with continuous 


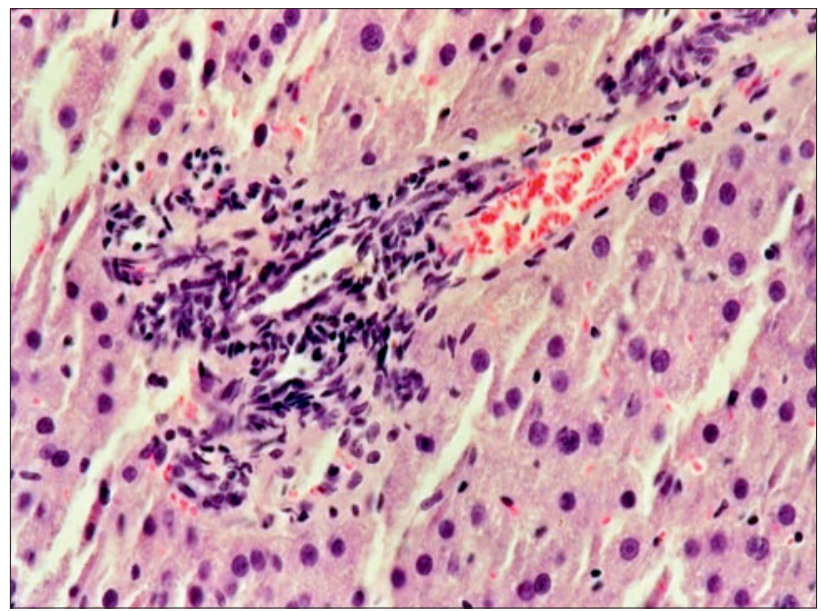

Fig. 1. Liver tissue sample of a $\mathrm{C} 1$ rat: periportal piecemeal and spotty hepatocyte necrosis $(\mathrm{HE}, \mathrm{x} 40)$.

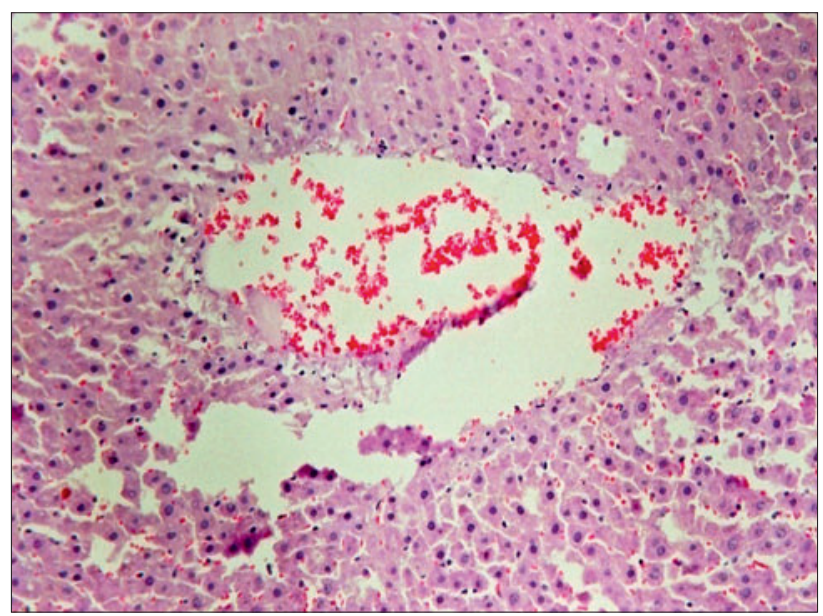

Fig. 2. Liver tissue sample of a I1 rat: recent haemorrhage and an area of acidophilic hepatocyte necrosis around it with surrounding incipient necrosis (HE, x20).

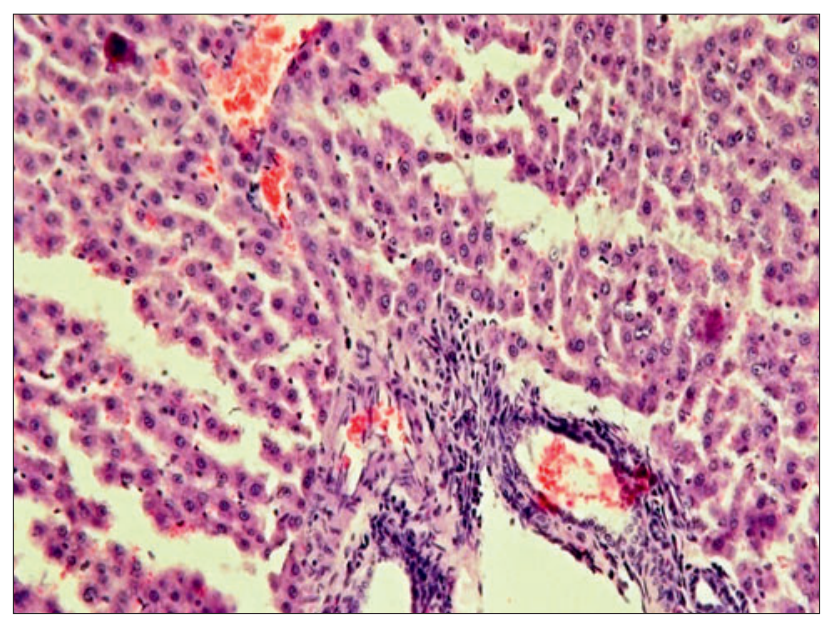

Fig. 3. Liver tissue sample of a I3 rat: piecemeal necrosis, lymphocytes, macrophages and fibroblasts inside the acinus with central vein congestion and sporadic regenerative hepatocytes $(\mathrm{HE}, \mathrm{x20})$.

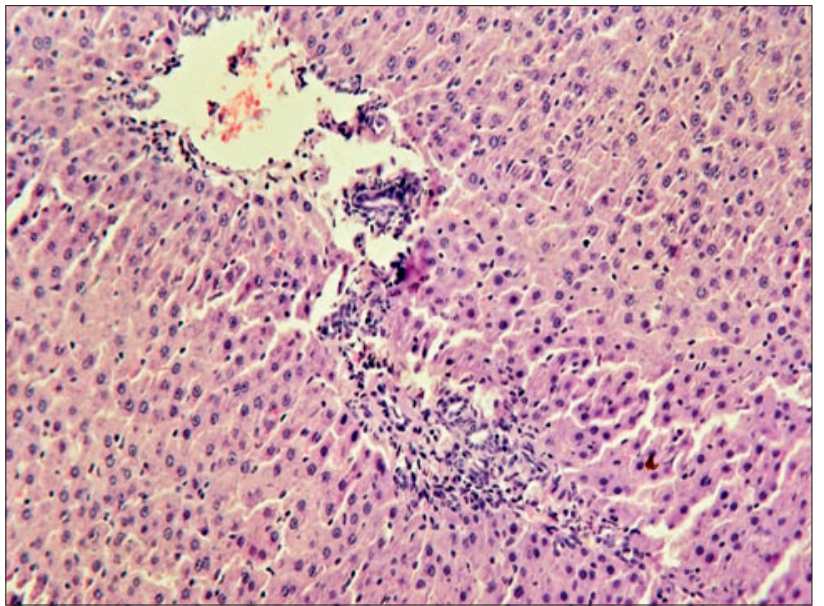

Fig. 4. Liver tissue sample of a $\mathrm{C} 3$ rat: bridging and spotty necrosis with microvacuolar degeneration $(\mathrm{HE}, \mathbf{x 2 0})$.

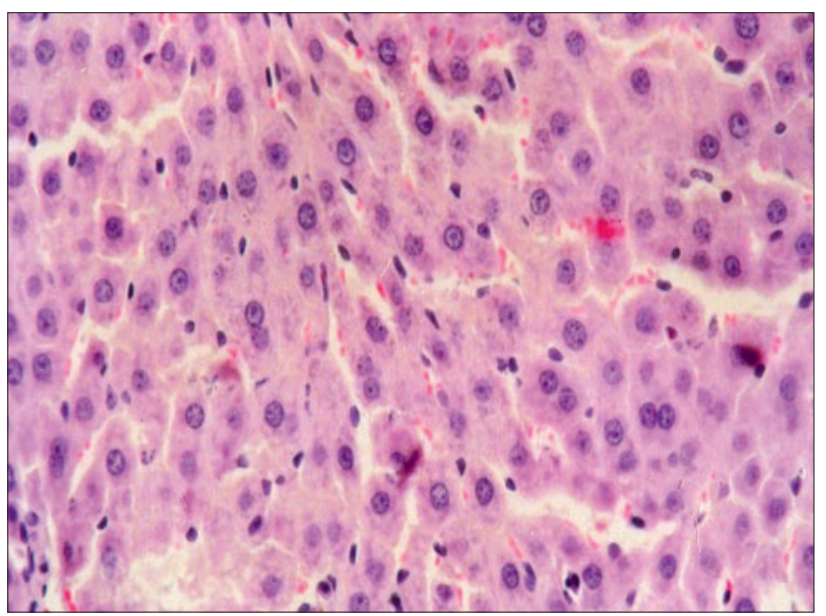

Fig. 5. Liver tissue sample of a $I 7$ rat: regenerative hepatocytes and fibroblasts without collagen (HE, x40).

HPC and second POD in rats with intermittent HPC) and presence of necrosis (1, 2, 3 and 7 POD in animals with continuous HPC). Compared to each other, LDH activity was significantly higher in $\mathrm{C} 1, \mathrm{C} 3$ and $\mathrm{C} 7$ subgroups than in I1, I2 and I7 subgroups, which also demonstrated a poorer liver tolerance to continuous inflow vascular occlusion. Serum LDH activity was significantly lower in both groups (I and C) during the whole period of examination (1, 2, 3 and 7 POD) compared to CG. ALP is the enzyme of bile duct epithelial cells and its activity reflects cholestasis more than ischemia. Therefore, this result suggested that biliary retention in presented experimental model was not sufficient to produce cholestatic liver damage and correlated with previously reported data (9).

The results of HP analysis were concurrent of those from biochemical examination. More intense, diverse and diffuse HP findings (different types of degeneration and necrosis), their earlier occurrence, longer persistence and slower regression with poorer, only sporadic regeneration in liver tissue samples of rats with continuous HPC clearly indicated a better tolerance to intermittent inflow hepatic vascular occlusion. 
$3-6$

\section{Conclusion}

The results of the presented study distinctly demonstrated more severe liver I/R injury after a continuous HPC. Therefore, if necessary, Pringle maneuver should be applied intermittently rather than continuously. An intermittent inflow vascular occlusion acts as ischemic preconditioning of the liver and, thus, reduces I/R parenchymatous injury.

\section{References}

1. Belghiti J, Noun R, Malafosse R, Jagot P, Sauvanet A, Pierangeli F et al. Continuous versus intermittent portal triad clamping for liver resection: a controlled study. Ann Surg 1999; 229: 369-375.

2. Chiappa A, Makuuchi M, Zbar AP, Biella F, Vezzoni A, Pozzi S et al. Comparison of continuous versus intermittent hepatic pedicle clamping in an experimental model. Hepatogastroenterology 2001; 48: 1416-1420.

3. Helewski K, Kowalczyk-Ziomek G, Czecior E, Wyrobiec G, Harabin-Slowinska M, Juszko-Piekut M et al. Protective effect of intermittent clamping of the portal triad in the rat liver on liver ischemia-reperfusion injury. Hepat Mon 2011; 11: 445-451.

4. Dixon E, Vollmer CM Jr, Bathe OF, Sutherland F. Vascular occlusion to decrease blood loss during hepatic resection. Am J Surg 2005; 190: 75-86.

5. Zhou L, Rui JA, Zhou RL, Peng XM, Wang SB, Chen SG et al. Liver injury after intermittent or continuous hepatic pedicle clamping and its protection by reduced glutathione. Hepatobiliary Pancreat Dis Int 2004; 3: 209-213.

6. van Gulik TM, de Graaf W, Dinant S, Busch ORC, Gouma DJ. Vascular occlusion techniques during liver resection. Dig Surg 2007; 24: 274-281.

7. van Wagensveld BA, van Gulik TM, Gelderblom HC, Scheepers JJ, Bosma A, Endert $\mathbf{E}$ et al. Continuous or intermittent vascular clamping during hemihepatectomy in pigs: hyaluronic acid kinetics in the assessment of early microvascular liver damage. Eur J Surg 2000; 166: 255-261.

8. Wu CC, Hwang CR, Liu TJ, P'Eng FK. Effects and limitations of prolonged intermittent ischaemia for hepatic resection of the cirrhotic liver. Br J Surg 1996; 83: 121-124.

9. Elias D, Desruennes E, Lasser P. Prolonged intermittent clamping of the portal triad during hepatectomy. Br J Surg 1991; 78: 42-44.

Received March 30, 2012. Accepted April 4, 2012. 